\title{
Introducing the Ongoing Clinical Trials in the Surgical Oncology Series
}

\author{
Jonathan M. Hernandez, $\mathrm{MD}^{1}$, and Kelly M. McMasters, MD, $\mathrm{PhD}^{2}$ \\ ${ }^{1}$ Surgical Oncology Program, National Cancer Institute, National Institutes of Health, Bethesda, MD; ${ }^{2}$ The Hiram C. Polk, \\ Jr. Department of Surgery, School of Medicine, University of Louisville, Louisville, KY
}

The management of patients with solid tumors has evolved in the last several decades coincidently with our understanding of disease biology. ${ }^{1}$ The paradigm shifts have been fueled by an explosion of molecular classifications $^{2}$ and the birth of targeted therapy, ${ }^{3}$ and more recently, by immunotherapy. ${ }^{4}$

The volume of data available to practicing clinicians has led to specialization of care providers such that many of us see patients with disease limited to one or two organs. This specialization has certainly made it easier to keep abreast of the latest research for a given disease, and initiatives such as The Landmark Series ${ }^{5}$ have facilitated the acquisition of disease-specific knowledge from gold standard randomized, prospective trials. Nevertheless, "questions" far outnumber "answers," and clinical dilemmas without data to support a decision are frequent, often transcending the organ-specific structure of today's clinical departments.

How do we manage the patient with oligometastatic progression controlled via immunotherapy? Should aggressive tumor genomics or biomarkers alter the recommended sequence of therapy options? What role or roles does regional therapy play in the management of metastatic disease? These situations emphasize the need to keep informed of ongoing research in multiple arenas, which we argue is nearly impossible currently. Resources are available (e.g., clinicaltrials.gov) ${ }^{6}$ of course, but navigation can

(C) This is a U.S. government work and not under copyright protection in the U.S.; foreign copyright protection may apply 2021

First Received: 9 April 2021

Accepted: 10 April 2021;

Published Online: 12 May 2021

J. M. Hernandez, MD

e-mail: jonathan.hernandez@nih.gov be cumbersome. In our society, information is immediate, visually appealing, and readily digestible. Why should information relevant to cancer surgery be different?

The Ongoing Trials in Surgical Oncology Series provides this level of information through visual abstracts backed by insight from the principal investigators. We started with colon cancer ${ }^{7-10}$ and will rotate the focus on a monthly basis. We aim to circumvent the time constraints that limit all of us by providing trial information across all the disciplines within surgical oncology in an easily assimilable format. We envision that this series will serve as the impetus for new trial ideas, bringing potential investigators together to facilitate multi-institution collaborations, and provide awareness about options for patients to streamline referrals.

We all are familiar with the suboptimal survival curves for each solid tumor type ${ }^{11}$ and painfully aware that they reflect the experiences of our patients. The clinical trial is an application for improved outcomes within the confines of scientific rigor. The argument certainly could be made that all patients should be enrolled in a trial, at least at some point during the course of their disease. We hope that the Ongoing Clinical Trials in Surgical Oncology series is a step in that direction.

\section{REFERENCES}

1. National Cancer Institute. Milestones in cancer research and discovery. https://www.cancer.gov/research/progress/250-yearsmilestones. Retrieved 6 Apr 2021.

2. Hoadley KA, Yau C, Wolf DM, et al. Multiplatform analysis of 12 cancer types reveals molecular classification within and across tissues of origin. Cell. 2014;158:929-44.

3. Flaherty KT, Gray RJ, Chen AP, et al. Molecular landscape and actionable alterations in a genomically guided cancer clinical trial: National Cancer Institute Molecular Analysis for Therapy Choice (NCI-MATCH). J Clin Oncol. 2020;38:3883-94. 
4. Yap TA, Parkes EE, Peng W, Moyers JT, Curran MA, Tawbi HA. Development of immunotherapy combination strategies in cancer. Cancer Discov. 2021;11:1-30.

5. McMasters KM. Introducing the landmark series. Ann Surg Oncol. 2020;27:1-2.

6. National Institutes of Health, U.S National Library of Medicine. h ttps://clinicaltrials.gov/ct2/home. Retrieved 6 Apr 2021.

7. Verbus EA, Rossi AJ, Luna AJ, Iqbal A, Morris VK, Hernandez JM. Circulating tumor DNA as a predictive biomarker in adjuvant chemotherapy in patients with stage IIA colon cancer (COBRA). Ann Surg Oncol. 2021. https://doi.org/10.1245/s10434-021-1011 2-z.

8. Rossi AJ, Khan TM, Hong H, Lesinski GB, Christina Wu C, Hernandez JM. Pepinemab (anti-SEMA4D) in combination with ipilimumab or nivolumab for patients with resectable pancreatic and colorectal cancer. Ann Surg Oncol. 2021. https://doi.org/10. 1245/s10434-021-10111-0.
9. Rossi AJ, Khan TM, Rehman SU, Nash GM, Hernandez JM. Early postoperative intraperitoneal vs hyperthermic intraperitoneal chemotherapy after optimal cytoreductive surgery for CRC with isolated peritoneal metastasis (ICARuS). Ann Surg Oncol. 2021. https://doi.org/10.1245/s10434-021-10110-1.

10. Khan TM, Verbus EA, Rehman SU, Chun YS, Hernandez JM. The role of liver resection for patients with liver and unresectable lung colorectal metastases (LUNA). Ann Surg Oncol. 2021. https://doi.org/10.1245/s10434-021-10109-8.

11. Siegel RL, Miller KD, Jemal A. Cancer statistics, 2020. $C A$ Cancer J Clin. 2020;70:7-30.

Publisher's Note Springer Nature remains neutral with regard to jurisdictional claims in published maps and institutional affiliations. 